\title{
Exploring the knowledge of student nurses about children who are overweight/obese
}

\author{
Tuan-I Tsai*1,2, Lauretta Luck $^{1,3}$, Diana Jefferies ${ }^{1}$, Lesley Wilkes ${ }^{1}$ \\ ${ }^{1}$ School of Nursing and Midwifery, Western Sydney University, Australia \\ ${ }^{2}$ Department of Nursing, Chung Hwa University of Medical Technology, Taiwan, China \\ ${ }^{3}$ Centre for Nursing and Midwifery Research, Nepean Hospital, Nepean Blue Mountains Local Health District, Australia
}

Received: May 12, 2019

DOI: $10.5430 /$ cns.v7n4p63
Accepted: October 15, 2019

Online Published: November 1, 2019

URL: https://doi.org/10.5430/cns.v7n4p63

\begin{abstract}
Objective: The prevalence of childhood overweight/obesity has increased in many countries worldwide. Children who are overweight/obese are at a higher risk of negative health outcomes. It is important to educate nursing students in their undergraduate studies to understand weight issues and therefore to help children manage overweight/obesity during childhood. The aim of this study was to compare the knowledge of childhood overweight/obesity between two cohorts (2-year program and 4-year program) of undergraduate nursing students at a University in South Taiwan.

Methods: Quantitative data were collected with a translated self-administered questionnaire. Survey results were analysed using descriptive statistics, including frequency counts and percentages. A $T$-test was used to compare the responses between the two groups of students.

Results: The findings of the survey demonstrated that nursing students in Taiwan have a good general knowledge about this issue. However, the results showed that the majority of students lacked knowledge about the measurement of children's BMI. Further, only a small percentage of students could recognize health risks that could be caused by childhood overweight/obesity.

Conclusions: As the rates of childhood overweight/obesity continues to rise, it is essential that students receive the appropriate training to enable them to provide all their paediatric patients and their families with guidance and support about this health issue.
\end{abstract}

Key Words: Overweight/obese, Knowledge, Nursing student, Taiwan

\section{INTRODUCTION}

The number of overweight/obese children has increased worldwide. In 2014, an estimated 41 million children who were overweight or obese were under the age of five and nearly half of them lived in Asia. ${ }^{[1]}$ The prevalence of childhood overweight/obesity has escalated in the last decades in Taiwan. About $28.7 \%$ of children in elementary school and $29.2 \%$ in junior high school are classified as overweight/obese in Taiwan. ${ }^{[2]}$
Nurses work with children in many different settings, such as hospitals, primary health care settings and schools. It is important for nurses to help children deal with overweight/obesity during childhood, so they can avoid serious consequences for their health and wellbeing later in life. In previous studies, there were other factors that could affect nurses dealing with childhood overweight/obesity. Communications skills ${ }^{[3]}$ lack of time and lack of resources ${ }^{[4,5]}$ are other factors reported in the literature. However, it has been suggested by a number of researchers that a lack of knowl-

\footnotetext{
*Correspondence: Tuan-I Tsai; Email: T.Tsai@ westernsydney.edu.au; Address: Western Sydney University, Locked Bag 1797, Penrith South, 2751,
} Australia. 
edge on weight issues was the one of the main reasons that nurses cannot provide appropriate advice and management to children who were overweight ${ }^{[4-6]}$ Considering the importance of this global problem in children's health and the long term effects, current and future nurses need to develop accurate knowledge about overweight/obese individuals.

Centers for Disease Control and Prevention $(\mathrm{CDC})^{[7]}$ reported that body mass index (BMI) is the standard method to determine childhood overweight/obesity. In children and adolescents, it is an age- and gender-specific measure, and one of the standardised ways to determine childhood overweight/obesity. "Overweight is defined as a BMI at or above the 85th percentile and below the 95th percentile for children and teens of the same age and sex. Obesity is defined as a BMI at or above the 95th percentile for children and teens of the same age and sex." ${ }^{[7]}$ (par.1)

Children who are overweight/obese are at a higher risk of short-term and long-term health implications and are at a higher risk of becoming overweight/obese adults. This has important implications for the community and for nurses improving care to the children and their family. The economic costs of overweight/obesity to the healthcare system and loss of productivity are considerable. There is also a substantial economic burden placed on families and communities.

The interaction between a child's family and the social context could influence the risk of a child becoming overweight/obese. Familial factors include parents' patterns of dietary intake and nutritional knowledge. Parenting style was also associated with a risk of childhood obesity. ${ }^{[8]}$ The studies demonstrated that when parents provide healthy eating patterns early in their children's lives, the obesity risk can be reduced. ${ }^{[9-11]}$ Societal factors include school or childcare facilities. ${ }^{[12]}$ Centers for Disease Control and Prevention ${ }^{[13]}$ suggested that the early child care setting may influence what children eat and their activity and this helps children develop healthy lifestyle habits. To reduce childhood overweight/obesity, school nurses reported that schools should offer healthy lunches and eliminate "junk food" vending machines ${ }^{[14]}$ It is evident that children have an increased risk of becoming overweight/obese due to lifestyle factors such
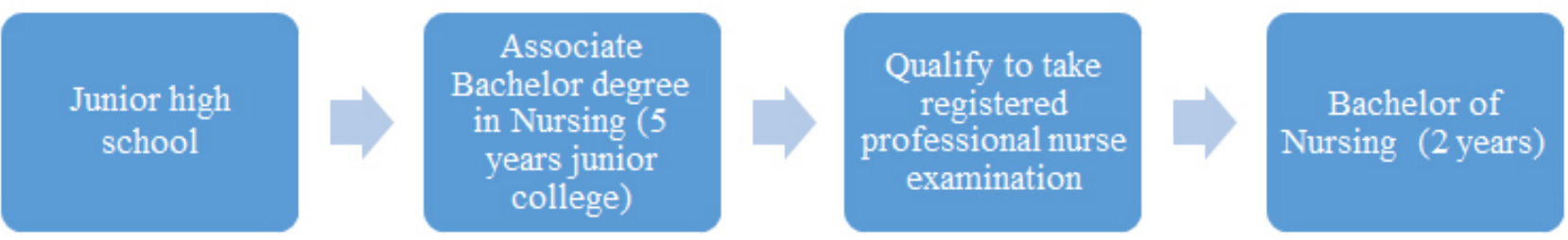

\section{MethodS}

\subsection{Design}

A descriptive survey design was used. Quantitative data were collected with a translated self-administered questionnaire.

\subsection{Participants recruitment}

Participants were recruited from two different final year undergraduate nursing programs (2-year program and 4-year program) at a University in South Taiwan. Nursing students in this study go through different pathways to obtain a Bachelor degree.

The 2-year program offers training for nursing graduates following a 5-year junior college Associate Bachelor degree, which admits graduates from junior high schools (see Figure 1). The 4-year program accepts students who graduate from senior high school. Both programs lead to a Bachelor of Nursing degree after completion of the course (see Figure 2). Student nurses' clinical experience is predominantly in the hospital and community care setting.

Figure 1. 2-year Bachelor of Nursing program progression

as their diet as well as their level of physical activity. ${ }^{[15]}$

Understanding nursing students' knowledge about overweight/obese children can help nurse education facilities improve the curriculum related to this issue. This will prechildren and their families. This paper reports on a study that assessed the knowledge of final year graduates about childyear program and 4-year program) in Taiwan. This study will provide the first data on the knowledge of nursing students With the rising rates of obesity in childhood in Asia and other parts of the world, it is important to identify exactly how and where education programs for student nurses should be targeted. Therefore this survey provides direction for future educational curricula. The aim of this study was to compare the knowledge of childhood overweight/obesity between two cohorts of undergraduate nursing students at a University in South Taiwan. 

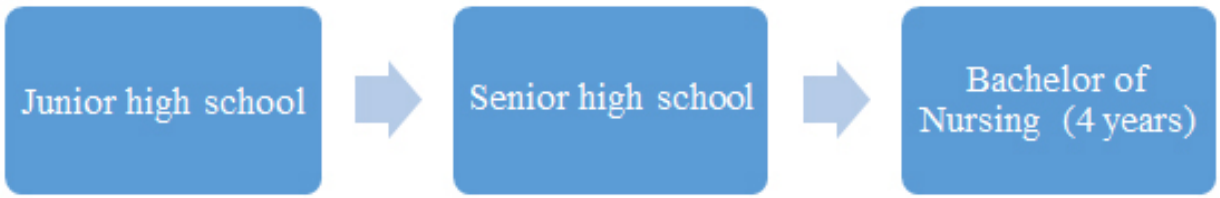

Qualify to take

registered

professional nurse examination

Figure 2. 4-year Bachelor of Nursing program progression

The participants from the 2-year program completed Paediatric Nursing and had at least 1,016 hours of clinical experiences in the 5-year junior college (before enter the 2-year program). During the 2-year program, the students are require to complete Child Health Nursing and may be placed in the different wards during the placement. For example, the students may go to surgical ward for the first placement, then medical ward and paediatric ward for the second and third placement. Alternatively, they may go to community centre for the first placement, medical and surgical ward for the second and third placement. The participants from the 4-year program completed Paediatric Nursing and had 1,016 hours of clinical experience. Paediatric Nursing teach students to understand the care of common medical disorders, promote health status and implement family-centred care for all children.

\subsection{Data collection}

A hard copy of the translated questionnaire was given to the students during their weekly informal student meeting. One hundred and two (49\%) of 2-year program nursing students and $106(51 \%)$ of 4-year program nursing students participated the study. A Plain Language Statement (PLS) that was developed in English and then translated to Mandarin was given to the participants.

\subsection{Tool}

This paper discusses the knowledge items from the survey from a larger study that explored two groups of Taiwanese nursing student's attitudes and knowledge about childhood overweight/obesity in Taiwan. The items used in the present study were based on the current literature about overweight/obesity. ${ }^{[4,16]}$ The survey consisted of 11 general knowledge items about childhood overweight/obesity, and the participants responded either "correct", "incorrect" or "don't know". In addition, there were two multiple choice items that explored the students' knowledge about BMI, the participants were asked to select the one correct answer from each of these two items. The final item related to the health risks associated with childhood overweight/obesity. The participants had the option to select more than one answer from the list of health risks. Demographic data were collected including age, gender, height and weight. To ensure content validity, the survey was reviewed by paediatric nurse edu- cators, nurse academics, and nurse researchers. The survey tool, originally written in English, was translated to Mandarin. The translation process included forward translation from English to Mandarin by a trained translator and backward translation of the Mandarin into English by a different translation agent. ${ }^{[17]}$ Details about this procedure can be found in. ${ }^{[18]}$

\subsection{Data analysis}

Survey results were analysed using descriptive statistics, including frequency counts and percentages. A t-test was used to compare the responses between the two groups of students. There was no significant relationship between the attitudes of the participants and their knowledge.

\subsection{Ethics}

The study was approved by the Human Research Ethics Committee (HREC) of Western Sydney University and from the relevant University in Taiwan. This included permission to collect data from the nursing students. All participants were told that participation was voluntary and they had right to withdraw without any consequence. Consent was implied following completion of the survey.

\section{ReSUlts}

There were 102 participants from the 2-year program and 106 from the 4-year program, a total of 208 final year nursing students attending the University in South Taiwan.

The majority of the 2-year program students $(96.1 \%, \mathrm{n}=98)$ and students in the 4-year program $(84.9 \%, \mathrm{n}=90)$ were female. Most students in both the 2-year program $(88.2 \%, \mathrm{n}$ $=90)$ and the 4-year program $(97.2 \%, \mathrm{n}=103)$ were aged between 21-29. The BMI of the students was calculated based on their weight and height. The majority of the 2-year program students $(70.6 \%, \mathrm{n}=72)$ and the 4-year program students $(59.4 \%, \mathrm{n}=63)$ were considered within the normal weight percentile.

As indicated in Table 1, students in both cohorts knew that normal weight is important for health (item 22 - 2-year program: $96.1 \%$; 4-year program: $98.1 \%$ ), that the number of overweight/obese children is increasing in Taiwan (item 32 2-year program: $96.1 \%$; 4-year program: $89.6 \%$ ) and that a sedentary lifestyle can cause childhood overweight/obesity 
(item 23 - 2-year program: 87.3\%; 4-year program: 86.8\%). rect answer on item 24; children from higher socio-economic However, only $13.7 \%(n=14)$ of 2-year program students status are less likely to be overweight/obese than children of and $5.7 \%(n=6)$ of 4-year program students reported the cor- lower socio-economic status.

Table 1. Comparison of 2-year program $(n=102)$ and 4-year program $(n=106)$ students' knowledge about childhood overweight/obesity (from highest to lowest correct response)

\begin{tabular}{|c|c|c|c|c|}
\hline Item & $\begin{array}{l}\text { Correct } \\
\text { answer }\end{array}$ & Program & $\begin{array}{l}\text { Number of } \\
\text { students providing } \\
\text { correct response }\end{array}$ & $\%$ \\
\hline \multirow{2}{*}{ 22. Normal weight is important for health. } & \multirow{2}{*}{ true } & 2-year & 98 & 96.1 \\
\hline & & 4-year & 104 & 98.1 \\
\hline \multirow{2}{*}{$\begin{array}{l}\text { 32. The prevalence of overweight/obese children has gradually increased in } \\
\text { Taiwan. }\end{array}$} & \multirow{2}{*}{ true } & 2-year & 98 & 96.1 \\
\hline & & 4-year & 95 & 89.6 \\
\hline \multirow{2}{*}{$\begin{array}{l}\text { 23. The prevalence of childhood overweight/obesity has increased in recent } \\
\text { years because of a sedentary lifestyle, e.g. watching TV and playing computer } \\
\text { games. }\end{array}$} & \multirow{2}{*}{ true } & 2-year & 89 & 87.3 \\
\hline & & 4-year & 92 & 86.8 \\
\hline \multirow{2}{*}{$\begin{array}{l}\text { 25. Most children who are overweight/obese are at a higher risk of becoming } \\
\text { overweight/obese adults. }\end{array}$} & \multirow{2}{*}{ true } & 2-year & 88 & 86.3 \\
\hline & & 4-year & 81 & 76.4 \\
\hline \multirow{2}{*}{$\begin{array}{l}28 . \text { If a child eats more calories per day than he/she burns he/she will gain } \\
\text { weight. }\end{array}$} & \multirow{2}{*}{ true } & 2-year & 84 & 82.4 \\
\hline & & 4-year & 75 & 70.8 \\
\hline \multirow{2}{*}{ 29. Prevention of childhood obesity should emphasise losing weight. } & \multirow{2}{*}{ false } & 2-year & 73 & 71.6 \\
\hline & & 4-year & 69 & 65.1 \\
\hline \multirow{2}{*}{ 30. Children should be asked to finish meals even they aren't hungry. } & \multirow{2}{*}{ false } & 2-year & 79 & 77.5 \\
\hline & & 4-year & 77 & 72.6 \\
\hline \multirow{2}{*}{$\begin{array}{l}\text { 31. Children should be encouraged to participate in at least } 60 \text { minutes of } \\
\text { moderate to vigorous physical activity every day. }\end{array}$} & \multirow{2}{*}{ true } & 2-year & 66 & 64.7 \\
\hline & & 4-year & 68 & 64.2 \\
\hline \multirow{2}{*}{$\begin{array}{l}\text { 27. Most children who are overweight/obese inherit the problem from their } \\
\text { parents. }\end{array}$} & \multirow{2}{*}{ false } & 2-year & 52 & 51.0 \\
\hline & & 4-year & 62 & 58.5 \\
\hline \multirow{2}{*}{$\begin{array}{l}\text { 26. Most children who are overweight/obese suffer from a hormone problem } \\
\text { that causes them to be overweight/obese. }\end{array}$} & \multirow{2}{*}{ false } & 2-year & 43 & 42.2 \\
\hline & & 4-year & 49 & 46.2 \\
\hline \multirow{2}{*}{$\begin{array}{l}\text { 24. Children from higher socio-economic status are less likely to be } \\
\text { overweight/obese than children of lower socio-economic status. }\end{array}$} & \multirow{2}{*}{ true } & 2-year & 14 & 13.7 \\
\hline & & 4-year & 6 & 5.7 \\
\hline
\end{tabular}

Table 2. Comparison of the total knowledge scores between 2-year program and 4-year program students (total correct score is 11)

\begin{tabular}{lccccccc}
\hline & Program & $\boldsymbol{n}$ & Mean & Std. Deviation & Std. Error Mean & $\boldsymbol{t}$ & $\boldsymbol{p}$ \\
\hline $\begin{array}{l}\text { Correct Answer rate of } \\
\text { Knowledge items }\end{array}$ & 2-year & 102 & 7.70 & 1.514 & .150 & 1.764 & .079 \\
& 4-year & 106 & 7.34 & 1.400 & .136 & & \\
\hline
\end{tabular}

As indicated in Table 2, when scores for general knowledge were totalled, there was no significant difference in the score for the 2-year program $(M=7.70, S D=1.514)$ and 4-year program $(M=7.34, S D=1.400 ; t=1.764, p=.079)$.

There were two multiple choice items about BMI. When students were asked to answer an item about the definition of childhood obesity, only $9.8 \%(n=10)$ of the 2-year program students and $11.3 \%(n=12)$ of the 4-year program students correctly answered that childhood obesity is defined when a child's BMI equals or exceeds that of $95 \%$ of other children who are of the same age group and sex. When responding to 
the item asking when clinicians begin testing children's BMI, only $8.8 \%(n=9)$ of the 2-year program students and $5.7 \%$ $(n=6)$ of the 4-year program students reported the correct answer.

Table 3. Comparison of the 2-year program $(n=102)$ and 4-year program $(n=106)$ students' knowledge about health issues that could be caused by childhood overweight/obesity

\begin{tabular}{lcc}
\hline \multirow{2}{*}{ Item } & \multicolumn{2}{c}{ Program } \\
\cline { 2 - 3 } & 2-year n (\%) & 4-year n (\%) \\
\hline Type 1 DM & $80(78.4)$ & $85(80.2)$ \\
Sleep apnea & $56(54.9)$ & $42(39.6)$ \\
High cholesterol & $93(91.2)$ & $88(83.0)$ \\
Low self- esteem & $72(70.6)$ & $71(67.0)$ \\
Type 2 DM & $87(85.3)$ & $74(69.8)$ \\
Metabolic syndrome & $93(91.2)$ & $88(83.0)$ \\
Heart disease & $80(78.4)$ & $86(81.1)$ \\
Anxiety & $35(34.3)$ & $39(37)$ \\
Asthma & $23(22.5)$ & $18(17)$ \\
Depression & $47(46.1)$ & $32(30)$ \\
Don't know & $101(99.0)$ & $105(99.1)$ \\
\hline
\end{tabular}

In the final item where nursing students were asked to choose what health risks could be caused by childhood overweight/obesity, there were 10 issues to choose from and all except one issue was correct (Type 1 diabetes mellitus [DM] was incorrect). Only $6.8 \%(n=7)$ of 2 -year students and $2.8 \%(n=3)$ of 4-year students demonstrated that they understood the health risks correctly. The results in Table 3 indicated that less than $50 \%$ of students believed that childhood overweight/obesity could cause anxiety, asthma and depression. There was a significant difference in the mean score of this item for the 2-year program $(M=7.52, S D=$ 2.028) and 4-year program $(M=6.87, S D=1.967 ; t=2.353$, $p=.020)$ students.

\section{Discussion}

The aim of this study was to evaluate two groups of Taiwanese nursing students' knowledge of childhood overweight/obesity. The findings of the survey demonstrated that nursing students in Taiwan have a good general knowledge about this issue. However, the results showed that majority of students were lacking in knowledge about the definition of obesity and when to start testing children's BMI. Also, only a small percentage of students could recognise all health risks that could be caused by childhood overweight/obesity. This result is similar to a study conducted by DiNapoli et al. ${ }^{[4]}$ in the USA. Di Napoli's study revealed that only $12 \%(\mathrm{n}=4)$ of the paediatric nurses at the medical centre in their study could define paediatric obesity and $24 \%(n=8)$ of nurses could identify the health issues that paediatric obesity could lead to.

More than $96 \%$ of students in this study believed that maintaining normal weight is important for health. Nursing students in this study understood that a sedentary lifestyle in childhood contributed to overweight/obesity. The result is supported by other studies. ${ }^{[15,19,20]}$ However, less than half of the students were aware that children who are overweight/obese may suffer psychological disorders such as anxiety and depression. Evidence in the literature demonstrated that obese children and adolescents showed significant rates of depression, had low self-esteem, ${ }^{[21]}$ and anxiety. ${ }^{[22]}$ In Taiwan, children who are overweight/obese from lower social-economic status backgrounds have a higher risk of depression than normal weight children. ${ }^{[23]}$

Social-economic status can influence body weight, ${ }^{\text {[24-27] }}$ and this can be related to the economic status of the country. Generally, in high-income and more economic developed countries, like North America and Europe, children with lower social-economic status have higher risks of overweight/obesity. ${ }^{[27,28]}$ An international research study in 35 countries found that in most Western and Central European countries, children from less affluent families are at a higher risk of a becoming overweight. ${ }^{[25]}$ A study in Taiwan indicated that morbid obesity in adults was associated with low social-economic status indicted by a lower level of education and income. ${ }^{[24]}$ The current study in Taiwan indicated that nursing students are not aware that more attention needs to be paid to overweight/obese children from lower socioeconomic status families.

Clinical placement in education provides the experiential foundation for nursing students. During clinical placement, students can transfer abstract theory from the classroom to performance in the clinical environment. ${ }^{[29,30]}$ This study showed that there was a significant difference in the mean score of knowledge related to the health issues that caused by overweight/obese for the 2-year program and 4-year program students. The result may demonstrate that students in 2-year program have more clinical experience and a better understanding of the consequences of childhood overweight/obesity. Some studies have demonstrated that clinical placement can help nursing students to acquire appropriate knowledge. ${ }^{[31,32]}$

Overweight/obesity can increase the risk of many chronic dis- 
eases, ${ }^{[33]}$ and the costs of the treatment of related disease may result in economic burden to the health care sector. ${ }^{[34]}$ Understanding the importance of childhood overweight/obesity is especially relevant given its rise in prevalence. This paper reports the knowledge items from a larger study about Taiwanese students' attitude and knowledge of childhood overweight/obesity. The study can help us to see whether nursing students' knowledge is correlated with their attitudes as some research has found a positive correlation between knowledge and attitudes. ${ }^{[35,36]}$ Our findings also suggest that nursing students require more in-depth education about this issue, such as the effects of childhood overweight/obesity on health and the knowledge about identifying children at risk using the BMI. An extension in the curricula is needed so that the results of this study can be included in undergraduate nursing programs at Taiwanese universities.

A targeted educational response can be developed from the results of this survey. This would include how nurses identify overweight/obese children using a BMI. This information could be covered theoretically in the classroom and be practiced on clinical placement. Nurses should be taught the social context of overweight/obesity so that they understand that children from lower socio-economic groups are more likely to be overweight/obese due to poor nutritional choices such as low cost foods. Giving students more information about discussing better food options for children and their families should also be included in curricula. Finally, students need to have a fuller understanding of the risk of health conditions that may result from overweight/obesity in childhood. Students need to understand that an overweight/ obese child is at risk of developing mental illnesses such as depression and anxiety as well as physical illness such as asthma. However, the education program needs to emphasise that Diabetes Type 1 is not a result of overweight/obesity.

\section{Limitation}

The study was undertaken with a small sample of nursing students from Taiwan. Consequently, there is limited international generalizability to other undergraduate nursing students. Another limitation of the study was that the list of health issues that could be caused by childhood overweight/obesity was not exhaustive. The descriptive nature and structure of the knowledge section of the survey was not conducive to statistical analysis for validity and reliability. However, it allows us to look at possible relationships between variables and, in a descriptive way, examine nursing students' knowledge of overweight/obesity.

\section{Conclusions}

This study could be replicated in other University settings in Taiwan to avoid the limits to generalizability because of the small sample. As the rates of childhood overweight/obesity continues to rise, it is obvious that there is a need for education for nursing students about assessment and the consequences of childhood overweight/obesity. The findings of this study suggest that clinical placement provides a meaningful learning opportunity, where nursing students can integrate practice and theory. It is essential that students receive the appropriate training to enable them to provide all their paediatric patients and their families with guidance and support about childhood overweight/obesity.

\section{ACKNOWLEDGEMENTS}

The team wishes to thank the participating university and the students.

\section{Conflicts of InTEREST Disclosure}

The authors declare they have no conflicts of interest.

\section{REFERENCES}

[1] World Health Organization. Report of the commission on ending childhood obesity. 2016. Available from: http://apps . who.int/iris/bitstream/10665/204176 /1/9789241510066_eng.pdf?ua=1

[2] Health Promotion Administration, Ministry of Health and Welfare, Taiwan. 2016 Annual report of health promotion administration. 2016 Available from: https://www.hpa.gov.tw/EngPages/Detail . aspx?nodeid=1072\&pid $=7183$

[3] Edvardsson K, Edvardsson D, Hörnsten Å. Raising issues about children's overweight-maternal and child health nurses' experiences. Journal of Advanced Nursing. 2009; 65(12): 2542-2551. PMid: 19824905. https://doi.org/10.1111/j.1365-2648.2009.0 $5127 . \mathrm{x}$

[4] DiNapoli C, Sytnyk E, Waddicor C. Pediatric nurses' perceptions, attitudes, and knowledge of childhood obesity at an academic medical center. Bariatric Nursing and Surgical Patient Care. 2011; 6(3): 125-131. https://doi.org/10.1089/bar.2011.9954

[5] Steele RG, Wu YP, Jensen CD, et al. School nurses' perceived barriers to discussing weight with children and their families: A qualitative approach. Journal of School Health. 2011; 81(3): 128-137. PMid: 21332477. https://doi.org/10.1111/j.1746-1561.2010.0 $0571 . \mathrm{x}$

[6] Müllersdorf M, Zuccato LM, Nimborg J, et al. Maintaining professional confidence-monitoring work with obese schoolchildren with support of an action plan. Scandinavian Journal of Caring Sciences. 2010; 24(1): 131-138. PMid: 20070591. https ://doi.org/10.1 111/j.1471-6712.2009.00696.x

[7] Centers for Disease Control and Prevention. Defining childhood obesity. 2016. Available from: https://www.cdc.gov/obesity/ch 
ildhood/defining.html

[8] Kakinami L, Barnett TA, Séguin L, et al. Parenting style and obesity risk in children. Preventive Medicine. 2015; 75: 18-22. PMid: 25797329. https://doi.org/10.1016/j.ypmed.2015.03.00 5

[9] Daniels LA, Mallan KM, Battistutta D, et al. Child eating behavior outcomes of an early feeding intervention to reduce risk indicators for child obesity: The NOURISH RCT. Obesity. 2014; 22(5): E104E111. PMid: 24415390. https://doi.org/10.1002/oby. 2069 3

[10] Lee YC, Chuang HT. The effects of parental factors on the weight of school-aged children. Journal of Tzu Chi College of Technology. 2015; 24: 19-32.

[11] Wen X, Hui SSC. Chinese parents' perceptions of their children's weights and their relationship to parenting behaviours. Child: Care, Health \& Development. 2011; 37(3): 343-351. PMid: 21083690. https://doi.org/10.1111/j.1365-2214.2010.01166.x

[12] Davison KK, Birch LL. Childhood overweight: A contextual model and recommendations for future research. Obesity Reviews. 2001; 2(3): 159-171. PMid: 12120101. https://doi.org/10.1046/j. 1467-789x.2001.00036.x

[13] Centers for Disease Control and Prevention. Early Care and Education (ECE). 2017. Available from: https://www.cdc.gov/obes ity/strategies/childcareece.html

[14] Nauta C, Byrne C, Wesley Y. School nurses and childhood obesity: An investigation of knowledge and practice among school nurses as they relate to childhood obesity. Issues in Comprehensive Pediatric Nursing. 2009; 32(1): 16-30. PMid: 19263291. https ://doi.org/10.1080/01460860802610186

[15] Thibault H, Carriere C, Langevin C, et al. Prevalence and factors associated with overweight and obesity in French primary-school children. Public Health Nutrition. PMid: 22953729. 2013; 16(2): 193-201. https ://doi.org/10.1017/S136898001200359X

[16] Moyers P, Bugle L, Jackson E. Perceptions of school nurses regarding obesity in school-age children. The Journal of School Nursing. 2005; 21(2): 86-93. PMid: 15801874. https ://doi.org/10.1177/10 598405050210020501

[17] Brislin RW. The wording and translation of research instruments. In WJ Lonner \& JW Berry (Eds.), Field methods in cross-cultural research. Beverley Hills, CA: Sage; 1986. 137-164 p.

[18] Tsai TI, Luck L, Jefferies D, et al. Challenges in adapting a survey: Ensuring cross-cultural equivalence. Nurse Researcher. 2018; 26(1): 28-32. PMid: 29856168. https ://doi .org/10.7748/nr. 2018. e1581

[19] Katzmarzyk PT, Barreira TV, Broyles ST, et al. Relationship between lifestyle behaviors and obesity in children ages 9-11: Results from a 12-country study. Obesity. 2015; 23(8): 1696-1702. PMid: 26173093. https://doi.org/10.1002/oby. 21152

[20] LeBlanc AG, Katzmarzyk PT, Barreira TV, et al. Correlates of total sedentary time and screen time in 9-11 year-old children around the world: The international study of childhood obesity, lifestyle and the environment. PLoS One. 2015; 10(6): e0129622. PMid: 26068231. https://doi.org/10.1371/journal pone.0129622

[21] Sheslow D, Hassink S, Wallace W, et al. The Relationship between self-esteem and depression in obese children. Annals of the New York Academy of Sciences. 1993; 699(1): 289-291. PMid: 8267330. https ://doi.org/10.1111/j.1749-6632.1993.tb18869.x

[22] Vila G, Zipper E, Dabbas M, et al. Mental disorders in obese children and adolescents. Psychosomatic Medicine. 2004; 66(3): 387-394.
PMid: 15184702. https://doi.org/10.1097/00006842-200 405000-00018

[23] Lin FG, Hsieh YH, Tung HJ. Interactive effects of family socioeconomic status and body mass index on depression in school-aged children. Asia Pacific Journal of Clinical Nutrition. 2012; 21(1): 64-72.

[24] Chang HC, Yang HC, Chang HY, et al. Morbid obesity in Taiwan: Prevalence, trends, associated social demographics, and lifestyle factors. PLoS One. 2017; 12(2): e0169577. PMid: 28152059. https://doi.org/10.1371/journal.pone.0169577

[25] Due P, Damsgaard MT, Rasmussen M, et al. Socioeconomic position, macroeconomic environment and overweight among adolescents in 35 countries. International Journal of Obesity. 2009; 33(10): 1084 1093. PMid: 19621018. https://doi.org/10.1038/ijo. 2009 .128

[26] McMurray RG, Harrell JS, Deng S, et al. The influence of physical activity, socioeconomic status, and ethnicity on the weight status of adolescents. Obesity. 2000; 8(2): 130-139. PMid: 10757199. https ://doi.org/10.1038/oby.2000.14

[27] Wu S, Ding Y, Wu F, et al. Socio-economic position as an intervention against overweight and obesity in children: A systematic review and meta-analysis. Scientific Reports. 2015; 5(1): 11354. https://doi.org/10.1038/srep11354 PMid:26112253 PMCid:PMC4481703

[28] Wang Y, Lim H. The global childhood obesity epidemic and the association between socio-economic status and childhood obesity. International Review of Psychiatry. 2012; 24(3): 176-188. PMid: 22724639. https://doi.org/10.3109/09540261.2012.688195

[29] Günay U, Kılınc G. The transfer of theoretical knowledge to clinical practice by nursing students and the difficulties they experience: A qualitative study. Nurse Education Today. 2018; 65: 81-86. PMid: 29547811. https://doi.org/10.1016/j.nedt.2018.02.031

[30] Lisko SA, O'dell V. Integration of theory and practice: Experiential learning theory and nursing education. Nursing Education Perspectives. 2010; 31(2): 106-108.

[31] AL-Sagarat AY, ALSaraireh F, Masa'deh R, et al. The impact of a mental health clinical placement on the clinical confidence of nursing students in Jordan. Nurse Education Today. 2015; 35(6): 760764. PMid: 25743094. https://doi.org/10.1016/j.nedt. 201 5.02 .008

[32] Kimzey M, Mastel-Smith B, Alfred D. The impact of educational experiences on nursing students' knowledge and attitudes toward people with Alzheimer's disease: A mixed method study. Nurse Education Today. 2016; 46: 57-63. PMid: 27598794. https: //doi.org/10.1016/j.nedt.2016.08.031

[33] Centers for Disease Control and Prevention. Childhood Obesity Causes \& Consequences. 2016. Available from: https : //www.cd c.gov/obesity/childhood/causes.html

[34] Cawley J. The economics of childhood obesity. Health Affairs. 2010; 29(3): 364-371. PMid: 20194974. https://doi.org/10.1377/ hlthaff.2009.0721

[35] Askarian M, Memish ZA, Khan AA. Knowledge, practice, and attitude among Iranian nurses, midwives, and students regarding standard isolation precautions. Infection Control \& Hospital Epidemiology. 2007; 28(2): 241-244. PMid: 17265414. https ://doi .org/ $10.1086 / 510868$

[36] Kiyak E, Dayapoglu N. An evaluation of knowledge and attitudes toward epilepsy in Eastern Turkey. Epilepsy \& Behavior. 2017; 75 241-245. PMid: 28843950. https ://doi.org/10.1016/j.yebe h. 2017.06 .036 